\title{
PRAJA is overexpressed in glioblastoma and contributes to neural precursor development
}

\section{Joshua Shin ${ }^{1}$, Viveka Mishra², Eric Glasgow ${ }^{3}$, Sobia Zaidi, Kazufumi Ohshiro ${ }^{4}$, Bhargava Chitti ${ }^{5}$, Jian Chen ${ }^{9}$, Amee A. Kapadia ${ }^{6}$, Neha Rana$^{7}$, Lopa Mishra ${ }^{4}$ Chu- Xia Deng ${ }^{8}$, Shuyun Rao $^{4}$ and Bibhuti Mishra ${ }^{4}$}

${ }^{1}$ University of Virginia, Charlottesville, VA, USA

${ }^{2}$ Massachusetts Institute of Technology, Cambridge, MA, USA

${ }^{3}$ Department of Molecular Oncology, Georgetown University, Washington, DC, USA

${ }^{4}$ Center for Translational Medicine, Department of Surgery, George Washington University, Washington, DC, USA

${ }^{5}$ Department of Medicine, George Washington University, Washington, DC, USA

${ }^{6}$ John Hopkins University, Department of Chemical and Biomolecular Engineering, Baltimore, MD, USA

${ }^{7}$ McLean High School, McLean, VA, USA

${ }^{8}$ Faculty of Health Sciences, University of Macau, Macau SAR, China

${ }^{9}$ Department of Gastroenterology, Hepatology, \& Nutrition, The University of Texas M. D. Anderson Cancer Center, Houston, Texas, USA

Published: September 21, 2017

Copyright: Shin et al. This is an open-access article distributed under the terms of the Creative Commons Attribution License (CC-BY), which permits unrestricted use, distribution, and reproduction in any medium, provided the original author and source are credited.

This article has been corrected: Dr. Jian Chen was added to the author list.

The authors sincerely apologize for this oversight.

Original article: Genes\&Cancer. 2017;8:640-649. https://doi.org/10.18632/genesandcancer.151.

PMID: 28966725; PMCID: PMC5620009. 